|| ISSN(online): 2589-8698 || ISSN(print): 2589-868X || International Journal of Medical and Biomedical Studies

Available Online at www.ijmbs.info

PubMed (National Library of Medicine ID: 101738825)

Index Copernicus Value 2018: 75.71

Original Research Article

Volume 3, Issue 5; May: 2019; Page No. 245-247

\title{
CLINICAL SIGNIFICANCE AND CORRELATION OF INTRA-ABDOMINAL PRESSURE WITH THE OUTCOME
} OF PERFORATION PERITONITIS

Naveen Gupta ${ }^{1}$, Shilpi Gupta ${ }^{2^{*}}$

${ }^{1}$ Surgical Specialist, Composite Hospital, BSF, Tekanpur, Gwalior

${ }^{2}$ Medical Officer, Gajra Raja Medical College, Gwalior

Article Info: Received 14 April 2019; Accepted 20 May. 2019

DOI: https://doi.org/10.32553/ijmbs.v3i5.391

Corresponding Author: Dr. Shilpi Gupta

Conflict of interest: No conflict of interest.

\section{Abstract}

Background: A progressive increase in intra-abdominal pressure (IAP) may cause abdominal compartment syndrome (ACS) with organ dysfunction. However, it remains strangely underdiagnosed.

Objective: To correlate Intra-abdominal pressure with the outcome in perforation peritonitis patients.

Methods: An Observational study was done on 50 patients with perforation peritonitis and patients undergoing intervention in the form of either emergency laparotomy or drain placement. The abdominal pressures were indirectly determined by measuring urinary bladder pressure with a Foley's catheter. Pearson correlation was used to see relation between intra- abdominal pressure and outcome of peritonitis. SPSS version 16 (trial) was used for analysis.

Results: Mean intra-abdominal pressure during time of presentation to the hospital was $26.4 \pm 3.8 \mathrm{~cm} \mathrm{H}_{2} \mathrm{O}$. Among various morbidities following operation, surgical site infection was most common (36\%) followed by wound dehiscence (30\%). There was strong linear correlation between intra-abdominal pressure and factors determining morbidity such as surgical site infection, wound dehiscence, burst abdomen.

Conclusions: There is a strong correlation of various co morbidities with increased intra-abdominal pressure in patients with perforation peritonitis which was significant statistically.

Keywords: Intra- Abdominal Pressure, Intravescical pressure, perforation peritonitis, Abdominal Compartment Syndrome.

\section{Introduction}

One of the most shared surgical emergencies attended by a general surgeon is Perforation peritonitis due to perforation of hollow viscous organ. It requires imperative surgical management and is related with high rate of mortality and morbidity. Intra-abdominal pressure (IAP) is the pressure hidden within the abdominal cavity. ${ }^{1}$ Intraabdominal pressure increases because of following reasons such as peritonitis, ileus, a diffuse ascites, intra-abdominal hemorrhage, large intra-abdominal tumors, laparoscopic surgery, peritoneal dialysis, abdominal or pelvic trauma. ${ }^{2}$ Intraabdominal pressure can be resolute by measuring bladder pressure. ${ }^{3}$ Bladder pressure measurement is a method used in diagnosis and monitoring of abdominal compartment syndrome. Abdominal compartment syndrome represents the pathophysiologic consequence of a raised intra-abdominal pressure, various systems are involved in this syndrome. ${ }^{3}$ The increased intra-abdominal pressure is transmitted to the pleural space and the lung compliance decreases.
Further the combined increase in abdominal pressure and pleural pressure leads to a decrease in venous return, direct compression of the heart, and increased afterload (especially in the right ventricle). Perfusion to the intra-abdominal organs can be critically reduced by the combined effects of the decreased cardiac output, increased interstitial pressure, and increased outflow pressure. ${ }^{4}$ Increased recognition of its prevalence among the critically ill, combined with advances in both the diagnosis and management of intra-abdominal hypertension (IAH) and abdominal compartment syndrome (ACS), have resulted in significant improvements in patient survival. ${ }^{4,5}$ Normal IAP is approximately $5-7 \mathrm{mmHg}$ in the critically ill but varies by disease severity with an IAP of $20-30 \mathrm{mmHg}$ being common in patients with severe sepsis or an acute abdomen. ${ }^{1}$ The accuracy and reproducibility of IAP measurements are of paramount importance in the management of IAH/ACS. ${ }^{5}$ While direct intraperitoneal catheter determinations are ideal, a variety of less invasive techniques for determining IAP have been devised 
including measurement of intravesicular (bladder), intragastric, intracolonic, and intrauterine pressure. ${ }^{6}$ So this study was planned to correlate them.

\section{Materials and Methods-}

Study Design- Observational Parallel assessment analytical study.

Study Settings- Private hospitals in Gwalior, Madhya Pradesh.

Study Duration- 1-year July 2017 to June 2018.

Study Population- patients admitted in the hospital for perforation peritonitis.

Sample size- All the patients of perforation peritonitis admitted during the study period were taken as study unit and as sample size also. So, total 50 patients were studied.

Sampling Technique- Purposive Sampling Technique

Inclusion Criteria- Subjects aged 18 years and above with perforation peritonitis and patients undergoing intervention in the form of either emergency laparotomy or drain placement were included.

Exclusion Criteria- Pregnant patients, patients in whom catheterization was not possible, history of previous surgery and patients leaving against medical advice (LAMA) were excluded from the study.

Methodology- The abdominal pressures were indirectly resolute by measuring urinary bladder pressure with a Foley's catheter and patients were catheterized. The bladder was drained completely and then filled with $100 \mathrm{ml}$ of sterile saline through the Foley's catheter. The tubing of the collecting bag will be clamped. Then the catheter will be connected to a saline manometer. The symphysis pubis with the zero reference the pressure will be measured in centimeters of water at end-expiration.

Informed Consent- Written informed consent

Ethical Consideration- The approval was given by all the administrative committee of private hospitals.

Statistical Analysis- Data was analyzed using SPSS version 16 (Trial Version). Pearson correlation was used to see relation between intra- abdominal pressure and outcome of peritonitis. $P$ value less than 0.05 was considered statistically significant.

\section{Results:}

Table 1: Demographic and Clinical Parameters of the study Participants

\begin{tabular}{|c|c|}
\hline Parameters & Number (\%) \\
\hline Males & $39(78)$ \\
\hline Females & $11(22)$ \\
\hline Mean Age & $45.4 \pm 1.4$ years \\
\hline Duration of abdominal pain & $4.2 \pm 4.5$ days \\
\hline Mean IAP & $26.4 \pm 3.8 \mathrm{~cm}$ of $\mathrm{H}_{2} \mathrm{O}$ \\
\hline
\end{tabular}

As per table 1 it was seen that perforation peritonitis has male preponderance (78\%) with the mean age was $45.4 \pm 1.4$ years. Duration of abdominal pain was around 4.2 days, while the mean Intra-abdominal pressure was $26.4 \pm 3,8 \mathrm{~cm}$ of $\mathrm{H}_{2} \mathrm{O}$.

Table 2: Blood Parameters of study participants

\begin{tabular}{|l|l|}
\hline Parameters & Mean \pm SD \\
\hline Hemoglobin & $10.4 \pm 4.2$ \\
\hline Albumin` & $1.8 \pm 0.7$ \\
\hline Creatinine & $1.6 \pm 0.8$ \\
\hline
\end{tabular}

Table 2 shows the blood parameters of the participants at the time of presentation to the emergency the mean Hemoglobin was $10.4 \pm 4.2 \mathrm{gm} \%$ which was low as compared to other studies. Mean Albumin was $1.8 \pm 0.7$, while Serum Creatinine was $1.6 \pm 0.8$.

Table 3: Pre-Operative Signs and Symptoms

\begin{tabular}{|l|l|l|}
\hline Signs and Symptoms & Present (\%) & Absent (\%) \\
\hline Fever & 30 & 70 \\
\hline Constipation & 20 & 80 \\
\hline Vomiting & 60 & 40 \\
\hline Abdominal pain & 70 & 30 \\
\hline Guarding and rigidity & 80 & 20 \\
\hline
\end{tabular}

The most common pre-operative sign and symptom at the time of presentation was Guarding and rigidity (80\%) followed by abdominal pain in $70 \%$ of patients which are consistent feature of peritonitis. Vomiting in $60 \%$, while fever and constipation were seen less in these patients.

Table 4: Post-Operative Outcomes in the study participants

\begin{tabular}{|l|l|l|}
\hline Outcomes & Present (\%) & Absent (\%) \\
\hline Surgical site infection & 36 & 64 \\
\hline Burst Abdomen & 20 & 80 \\
\hline Wound Dehiscence & 30 & 70 \\
\hline ARDS & 8 & 92 \\
\hline Caecal Leak & 6 & 94 \\
\hline Post-op duration of stay & $7.6 \pm 4.2$ days \\
\hline
\end{tabular}

As per table 4 the most common post-operative morbidity was surgical site infection seen in $36 \%$ of patients, followed by wound dehiscence in $30 \%$. Burst 
Abdomen was also seen in $20 \%$ of cases. Post operative duration of stay was 7.6 \pm 4.2 days. These were the outcomes of Laparotomy and drain placement which further shows the impact of abdominal compartment syndrome.

Table 5: Correlation between IAP and Post -operative outcomes

\begin{tabular}{|l|l|l|}
\hline Outcomes & $\mathbf{r}$ & $\mathbf{p}$-value \\
\hline Surgical site infection & 0.98 & $0.01^{*}$ \\
\hline Burst Abdomen & 0.86 & $0.0 .1^{*}$ \\
\hline Wound Dehiscence & 0.77 & $0.02^{*}$ \\
\hline ARDS & -0.04 & 0.32 \\
\hline Caecal Leak & -0.09 & 0.27 \\
\hline
\end{tabular}

${ }^{*} p<0.05$ is statistically significant

There was strong linear correlation between intraabdominal pressure and various outcome measures. However, this was statistically highly significant. Negative correlation was seen with ARDS and Caecal Leak. Though SSI, burst abdomen, wound dehiscence showed positive correlation and was strong.

\section{Discussion:}

This Observational study was conducted in 50 patients with peritonitis. The mean age of the participants was 45.4 years which was like study conducted by Huysen et al. Males were most affected than females which were consistent with earlier studies. ${ }^{7,8}$ In present study, clinically the incidence of Surgical Site infection was more with intra-abdominal pressure greater than $25 \mathrm{~cm}$ of $\mathrm{H}_{2} \mathrm{O}$ however statistically it was significant. The presence of IAH is associated with an 11-fold increase in mortality compared with patients without $\mid \mathrm{AH} .{ }^{9}$ In this subgroup of patients, associated renal dysfunction was seen in patients and elevated IAP was found to have significant detrimental effect on blood urea, serum creatinine. ${ }^{10}$ Present study showed significant correlation with ARDS but some studies showing that $\mathrm{IAH}$ increases the risk of lung edema, decreases total respiratory system compliance. ${ }^{10}$ Cheatham et al had found that elevated IAP alone does not have enough sensitivity or specificity to be useful as a predictor of mortality. ${ }^{11}$ In a retrospective study of patients with secondary ACS, overall mortality was $60 \%$ with $43 \%$ mortality for those decompressed. ${ }^{11,12}$

\section{Conclusion}

There is increased risk of burst abdomen during increased intra-abdominal pressure as measured by change in intravescical pressure and there was raised incidence of surgical site infection in patients with perforation peritonitis following increased intraabdominal pressure. There is strong linear correlation of these co morbidities which was highly significant statistically.

\section{References}

1. Malbrain MLNG, Cheatham ML, Kirkpatrick A, Sugrue M, Parr M, De Waele J, et al. Results from the conference of experts on intra-abdominal hypertension and abdominal compartment syndrome. Part I: Definitions. Intensive Care Med. 2006;32:1722-32.

2. Tons C, Schachtrupp A, Rau M, Mumme T, Schumpelick V. Abdominal compartment syndrome: Prevention and treatment. Chirurg. 2000;71:918-26.

3. Iberti TJ, Kelly KM, Gentili DR, Hirsch S, Benjamin E. A simple technique to accurately determine intraabdominal pressure. Crit Care Med. 1987;15:1140-2.

4. Cheatham ML, Safcsak K. Is the evolving management of IAH/ACS improving survival? Acta Clinica Belgica. 2007;62(Supplement 1);268.

5. Malbrain MLNG, Jones F. Intra-abdominal pressure measurement techniques. RR, Cheatham ML, Malbrain MLNG, Sugrue $M$, editors. Abdominal Compartment Syndrome. Landes Biomedical, Georgetown. 2006.

6. Agrawal S, Chaudhary T, Sahu SK. Correlation of intraabdominal pressure with the outcome of perforation peritonitis. Int Surg J 2017;4:1584-7.

7. Pülat $H$, Karaköse $O$, Zihni I, Özçelik KÇ, Eken H, Çalta $A F$, et al. Effect of intraabdominal pressure values and Mannheim Peritonitis Index to prognosis of patients with acute abdomen. Int J Clin Exp Med. 2016;9(6):12032-8.

8. Jampani $S R$, Vattikonda $S$, Jampani $S$, Vasireddi V. Intra-abdominal pressure monitoring and outcome in patients with peritonitis.2016;3(4).

9. Khan S, Verma AK, Ahmad SM, Ahmad R. Analyzing intra-abdominal pressures and outcomes in patients undergoing emergency laparotomy. J emergencies, trauma, and shock. 2010;3(4):318.

10. Quintel M, Pelosi P, Caironi P, Meinhardt JP, Luecke T, Herrmann $P$, et al. An increase of abdominal pressure increases pulmonary edema in oleic acid-induced lung injury. Am J Respir Crit Care Med. 2004;169(4):53441.

11. Cheatham ML, White MW, Sagraves SG, Johnson JL, Block EF. Abdominal perfusion pressure: a superior parameter in the assessment of intra- abdominal hypertension. J Trauma. 2000;49:621-7.

12. Britt RC, Gannon T, Collins JN, Cole FJ, Weireter LJ, Britt LD. Secondary abdominal compartment syndrome: risk factors and outcomes. Am Surg. 2005;71:982-5. 